\title{
Epigenetic and transcriptional signatures of stable versus plastic differentiation of proinflammatory $\gamma \delta$ T cell subsets
}

\author{
Nina Schmolka ${ }^{1,5}$, Karine Serre ${ }^{1,5}$, Ana R Grosso ${ }^{1}$, Margarida Rei ${ }^{1,2}$, Daniel J Pennington ${ }^{2}$, Anita Q Gomes ${ }^{1,3}$ \& \\ Bruno Silva-Santos ${ }^{1,4}$
}

Two distinct subsets of $\gamma \delta$ T cells that produce interleukin 17 (IL-17) (CD27- $\gamma \delta \boldsymbol{\delta}$ T cells) or interferon- $\gamma$ (IFN- $\gamma$ ) (CD27+ $\gamma \delta$ T cells) develop in the mouse thymus, but the molecular determinants of their functional potential in the periphery remain unknown. Here we conducted a genome-wide characterization of the methylation patterns of histone $\mathrm{H3}$, along with analysis of mRNA encoding transcription factors, to identify the regulatory networks of peripheral IFN- $\gamma$-producing or IL-17-producing $\gamma \delta$ $\mathrm{T}$ cell subsets in vivo. We found that $\mathrm{CD}_{2} 7^{+} \gamma \delta \mathrm{T}$ cells were committed to the expression of Ifng but not $/ / 17$, whereas $\mathrm{CD}^{2} 7^{-} \gamma \delta$ T cells displayed permissive chromatin configurations at loci encoding both cytokines and their regulatory transcription factors and differentiated into cells that produced both IL-17 and IFN- $\gamma$ in a tumor microenvironment.

$\gamma \delta$ T cells have emerged as key providers of interleukin 17 (IL-17) in various models of infection, inflammation and autoimmunity ${ }^{1-6}$. Antibody-mediated or genetic depletion of $\gamma \delta$ T cells greatly reduces disease severity in IL-17-driven models of chronic inflammation ${ }^{1-4,7}$. Those results notwithstanding, many reports have made a compelling case for $\gamma \delta$ T cells as major producers of interferon- $\gamma$ (IFN- $\gamma$ ) in both mice and humans ${ }^{8}$, which has been a foundation for clinical trials targeting these lymphocytes in cancer immunotherapy ${ }^{9}$. Given the dual ability of $\gamma \delta$ T cells to produce IL-17 and IFN- $\gamma$, published work has aimed to identify markers associated with functional attributes of mouse $\gamma \delta$ T cells ${ }^{10-13}$. Expression of the costimulatory receptor CD27 segregates IL-17-producing $\left(\mathrm{CD} 27^{-}\right) \gamma \delta$ T cells and IFN- $\gamma$-producing $\left(\mathrm{CD} 27^{+}\right) \gamma \delta$ T cells in both naive and Plasmodium-infected C57BL/6 mice ${ }^{10}$. Moreover, the chemokine receptor CCR6, which is expressed exclusively on CD27$\gamma \delta \mathrm{T}$ cells, constitutes an additional marker for IL- $17^{+} \gamma \delta \mathrm{T}_{\text {cells }}{ }^{13,14}$.

Both $\mathrm{CD}_{27^{+}}$and $\mathrm{CD} 27^{-} \gamma \delta \mathrm{T}$ cell subsets show spontaneous cytokine secretion after activation, in contrast to the delayed differentiation of conventional CD4 $4^{+} \mathrm{T}$ cells of the $\mathrm{T}_{\mathrm{H}} 1$ or $\mathrm{T}_{\mathrm{H}} 17$ subset of helper $\mathrm{T}$ cells ${ }^{15}$. That finding is highlighted by the observation that $30-40 \%$ of peripheral $\gamma \delta$ T cells freshly isolated from naive mice produce either IL-17 or IFN- $\gamma$ after $3 \mathrm{~h}$ of restimulation in vitro ${ }^{10}$. Those functionally mature $\gamma \delta$ T cell subsets are also found in the thymus as early as the embryonic stages of mouse development ${ }^{10-12,16}$. Moreover, the expression of genes linked to the production of IL-17 or IFN- $\gamma$ segregates with particular $\gamma \delta$ thymocyte subsets ${ }^{17}$. However, the epigenetic 'landscape' of $\gamma \delta \mathrm{T}$ cells, which, as for CD $4^{+} \mathrm{T}$ cells ${ }^{18,19}$, probably dynamically controls the expression of genes encoding signature cytokines and their transcriptional regulators, remains unknown. Among other epigenetic mechanisms, methylation of histone $\mathrm{H} 3$ at Lys4 (H3K4me) or Lys27 (H3K27me) controls the accessibility of genes for the transcriptional machinery and thereby regulates cell fate ${ }^{19}$. Notably, the advent of deep (massive) sequencing, coupled to chromatin immunoprecipitation (ChIP), has allowed the genomewide characterization of $\mathrm{H} 3 \mathrm{~K} 4$ - and $\mathrm{H} 3 \mathrm{~K} 27$-methylation patterns in various cell types, including $\mathrm{CD}^{+}$helper $\mathrm{T}$ cell subsets that were differentiated in vitro ${ }^{18}$.

To gain insight into the epigenetic regulation of $\gamma \delta$ T cell subsets, we conducted genome-wide profiling of active dimethylated H3K4 (H3K4me2) and repressive trimethylated H3K4 (H3K4me2) modifications, complemented with analysis of additional chromatin marks (H3K36me3 and $\mathrm{H} 3$ acetylation) and transcriptional quantification of $\mathrm{CD}_{27^{+}} \gamma \delta\left(\gamma \delta 27^{+}\right) \mathrm{T}$ cell or CD27 ${ }^{-} \gamma \delta\left(\gamma \delta 27^{-}\right)$T cell subsets isolated from secondary lymphoid organs and compared those with the histone modifications and mRNA abundance in $\mathrm{T}_{\mathrm{H}} 1$ or $\mathrm{T}_{\mathrm{H}} 17 \mathrm{CD} 4^{+} \mathrm{T}$ cells differentiated in vitro. Our results constitute a public resource describing the epigenomes of $\gamma \delta 27^{+}$and $\gamma \delta 27^{-}$T cells and their effect on key transcriptional regulators of differentiation, and provide new insights on the peripheral functions of thymus-derived $\gamma \delta \mathrm{T}$ cell subsets.

\section{RESULTS}

Genome-wide analysis of $\mathrm{H} 3$ methylation in $\gamma \delta \mathrm{T}$ cell subsets To obtain a global profiling of chromatin modifications in $\gamma \delta \mathrm{T}$ cell subsets (isolated from pooled lymph nodes and spleen), we analyzed those cells by ChIP with antibody to H3K4me2 (anti-H3K4me2) and

${ }^{1}$ Instituto de Medicina Molecular, Faculdade de Medicina, Universidade de Lisboa, Lisbon, Portugal. ${ }^{2}$ Blizard Institute, Barts and The London School of Medicine, Queen Mary University of London, London, UK. ${ }^{3}$ Escola Superior de Tecnologia da Saúde de Lisboa, Lisbon, Portugal. ${ }^{4}$ Instituto Gulbenkian de Ciência, Oeiras, Portugal. ${ }^{5}$ These authors contributed equally to this work. Correspondence should be addressed to B.S.-S. (bssantos@fm.ul.pt) or A.Q.G. (anitagomes@fm.ul.pt). 

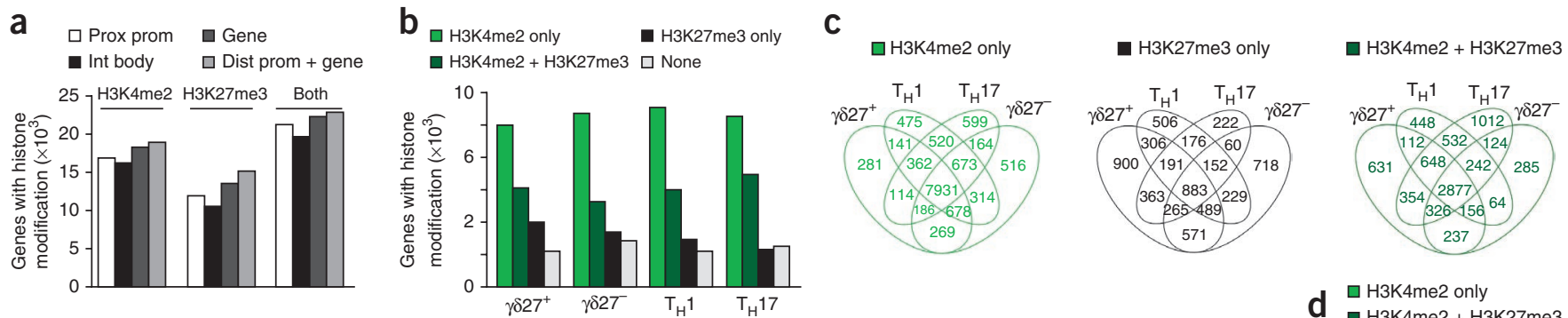

Figure 1 Genome-wide histone $\mathrm{H} 3$ methylation in subsets of $\gamma \delta \mathrm{T}$ cells and $\mathrm{CD} 4^{+}$helper T cells. (a) ChIP-seq quantification of genes associated with $\mathrm{H} 3 \mathrm{~K} 4 \mathrm{me} 2$ or H3K27me3 alone or H3K4me2 and H3K27me3 together (Both) in the total pool of $\gamma \delta 27^{+} \mathrm{T}$ cells, CCR6 $6^{+} \gamma 27^{-} \gamma \delta \mathrm{T}$ cells and $\mathrm{CD} 4^{+} \mathrm{T}_{H} 1$ and $\mathrm{T}_{H} 17$ cells, in the following genomic regions: distal promoter ( $-4 \mathrm{~kb}$ to $-1 \mathrm{~kb}$ upstream of the transcription start site) plus gene (Dist prom + gene); proximal promoter $(-1 \mathrm{~kb}$ to $+1 \mathrm{~kb}$ around the transcription start site; Prox prom); internal gene body ( $+1 \mathrm{~kb}$ from the start site to end of gene; Int body); and the gene (proximal promoter + internal gene body; Gene). (b) ChIP-seq quantification of genes associated with histone modifications as in a in each of the four T cell subsets in a. (c) Overlap of genes associated with histone modifications in the four T cell subsets in a, presented as Venn diagrams. (d) Frequency of genes with differences in modification in $\gamma \delta 27^{+}$ $\mathrm{T}$ cells versus (vs) $\gamma \delta 27^{-} \mathrm{T}$ cells (left) or $\mathrm{T}_{H} 1$ cells versus $\mathrm{T}_{H} 17$ cells (right) among those with H3K4me 2 or H3K27me 3 modifications or both $\mathrm{H} 3 \mathrm{~K} 4 \mathrm{me} 2$ and H3K27me3 modifications. Samples were analyzed a second time to ensure the technical reproducibility of ChIP-seq results; results were confirmed by ChIP-qPCR analysis of biological duplicates. Data are from one experiment with cells pooled from eight mice.

anti-H3K27me3, followed by deep sequencing (ChIP-seq). As reference, we differentiated $\mathrm{CD} 4{ }^{+} \mathrm{T}_{\mathrm{H}} 1$ and $\mathrm{T}_{\mathrm{H}} 17$ subsets by standard in vitro protocols and subjected those to the same ChIP-seq analysis. This confirmed published observations of $\mathrm{T}_{\mathrm{H}} 1$-biased Ifng expression and H3K4me2 marks in the Ifng locus ${ }^{18}$, which contrasted with the expression and $\mathrm{H} 3 \mathrm{~K} 4 \mathrm{me} 2$ modifications of Il17a in $\mathrm{T}_{\mathrm{H}} 17$ cells (Supplementary Fig. 1).

We subjected the ChIP-seq data to in-depth bioinformatics analysis. We used three different 'peak-calling' tools to detect enrichment for histone-modification density and assigned only peaks consistently retrieved by all three methods. We first examined the H3-methylation patterns, across the entire genome, in the total pool of $\mathrm{T}$ cell subsets under study: $\gamma \delta 27^{+}$and $\gamma \delta 27^{-} \mathrm{T}$ cells, and $\mathrm{T}_{\mathrm{H}} 1$ and $\mathrm{T}_{\mathrm{H}} 17$ cells. This revealed that the vast majority (95\%) of all $\mathrm{H} 3$-modified genes (in the total pool of T cell subsets) displayed the H3K4me2 or H3K27me3 marks in the promoter-proximal region (1 kilobase $(\mathrm{kb})$ upstream and downstream of transcription start site); we observed only a small increase in $\mathrm{H} 3$ modifications when we also considered the distal promoter region (Fig. 1a). High proportions of $\mathrm{H3}$-modified genes were associated with $\mathrm{H} 3 \mathrm{~K} 4 \mathrm{me} 2$ alone (50\%) or with both H3K4me2 or H3K27me3 marks (27\%), with similar patterns observed for all four $\mathrm{T}$ cell subsets (Fig. 1b). A smaller fraction of $\mathrm{H} 3$-modified genes $(<18 \%)$ displayed repressive H3K27me3 marks alone (Fig. 1b), with $4 \%$ (883 genes) of all $\mathrm{H} 3$-modified genes displaying only H3K27me3 marks concomitantly in all four T cell subsets (Fig. 1c). Quantitative analysis of the genes marked by H3K4me2 alone, H3K27me3 alone or both $\mathrm{H} 3 \mathrm{~K} 4 \mathrm{me} 2$ and $\mathrm{H} 3 \mathrm{~K} 27 \mathrm{me} 3$ revealed that from an epigenetic perspective, the $\gamma \delta 27^{+}$and $\gamma \delta 27^{-} \mathrm{T}$ cell subsets generated in vivo were as distinct from each other as were the $\mathrm{CD}^{+} \mathrm{T}_{\mathrm{H}} 1$ and $\mathrm{T}_{\mathrm{H}} 17$ cells subsets polarized in vitro (Fig. 1d).

We next focused our analysis on the two $\gamma \delta \mathrm{T}$ cell subsets and compared the H3-methylation densities of $\gamma \delta 27^{+}$and $\gamma \delta 27^{-} \mathrm{T}$ cells. On the basis of quantitative algorithms, a total of 10,581 genes had a difference in the abundance of either H3K4me2 or H3K27me3 marks (Fig. 2a,b). Those marks were located in the promoter-proximal region for $64 \%$ of all genes with a difference in $\mathrm{H} 3$ modification in $\gamma \delta 27^{+} \mathrm{T}$ cells versus $\gamma \delta 27^{-} \mathrm{T}$ cells (Fig. $2 \mathrm{a}$ ).

Selective inspection of the epigenetically regulated genes in $\gamma \delta 27^{+}$ and $\gamma \delta 27^{-} \mathrm{T}$ cell subsets indicated that genes linked to $(\gamma \delta) \mathrm{T}$ cell development (such as Bcl11b, Id 3 or $E t v 5)^{17}$ displayed almost identical histone marking in both subsets (Fig. 2c). In contrast, genes encoding effector cytokines (Il17a, Ill7f and Il22) showed substantially more enrichment for permissive H3K4me2 marks in $\gamma \delta 27^{-}$ $\mathrm{T}$ cells than in $\gamma \delta 27^{+} \mathrm{T}$ cells (Fig. $2 \mathrm{c}$ ). These epigenetic profiles suggested that $\gamma \delta 27^{+}$and $\gamma \delta 27^{-} \mathrm{T}$ cells share an early developmental program but diverge during functional differentiation into cytokineproducing subsets.

\section{Additional targets in the differentiation of $\gamma \delta \boldsymbol{\delta}$ cell subsets}

We next examined the full H3K4me2-H3K27me3 epigenome of $\gamma \delta 27^{+}$and $\gamma \delta 27^{-} \mathrm{T}$ cells (Supplementary Table 1 ) to identify genes encoding molecules involved in their differentiation. Ill 1 a, Ill $f f$ and Il22 were among the genes with the greatest difference between the two subsets in $\mathrm{H} 3$ modification, and all showed more enrichment for active H3K4me2 marks in $\gamma \delta 27^{-} \mathrm{T}$ cells than in $\gamma \delta 27^{+} \mathrm{T}$ cells (Supplementary Table 2). We noted the same pattern for $\mathrm{Ccr} 6$ (which encodes the chemokine receptor CCR6) and Illr1 and Il23r (which encode cytokine receptors) (Supplementary Table 2), all known to be expressed in $\gamma \delta 27^{-}$cells $1,13,14,20$. Those results notwithstanding, the 25 genes with the greatest difference in modification in $\gamma \delta 27^{+}$ $\mathrm{T}$ cells versus $\gamma \delta 27^{-} \mathrm{T}$ cells represented previously unknown targets for the development and function of $\gamma \delta \mathrm{T}$ cells (Supplementary Table 2). Dock 8 and $D k k 3$ displayed active H3K4me2 marks in $\gamma \delta 27^{-}$ $\mathrm{T}$ cells but not in $\gamma \delta 27^{+} \mathrm{T}$ cells. The guanine-exchange factor DOCK8 is a signaling adaptor that controls the survival and function of $\mathrm{CD} 8^{+}$ $\mathrm{T}$ cells ${ }^{21}$ and activation of $\mathrm{B}$ cells ${ }^{22}$. Moreover, DOCK8 mutation in humans causes severe combined immunodeficiency associated with high susceptibility to infection ${ }^{21,22}$. DKK3 is a glycoprotein that modulates Wnt signaling and has a regulatory function in $\mathrm{CD}^{+} \mathrm{T}$ cells $^{23}$.

While our analysis revealed many signaling mediators and transcription factors of unknown function in $\gamma \delta \mathrm{T}$ cells (or T cells in general), various candidates were among the proteins with receptor activity (Supplementary Table 2): the costimulatory receptor SLAMF1 (CD150), which controls the development of natural killer (NK) T cells ${ }^{24}$ and promotes inflammation in a mouse model of colitis $^{25}$; the scavenger receptor SCARF 1 , which recognizes and triggers innate immune responses to fungi ${ }^{26}$; $\mathrm{EPHB} 2$, which orchestrates 

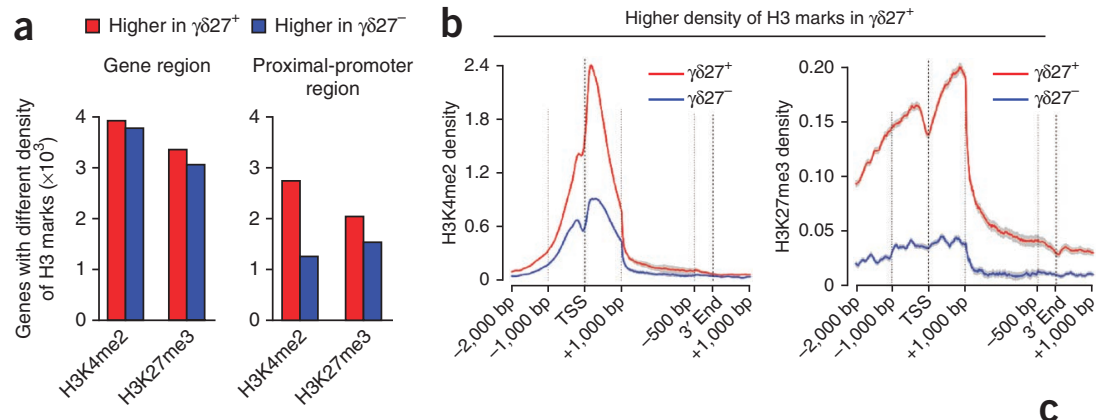

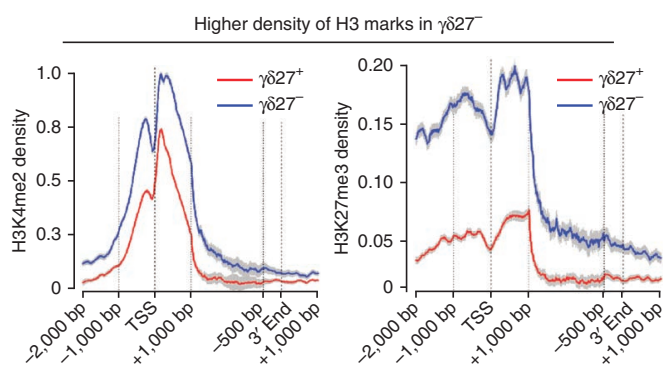

C $\gamma \delta 27^{+} \quad \gamma \delta$ T cell development
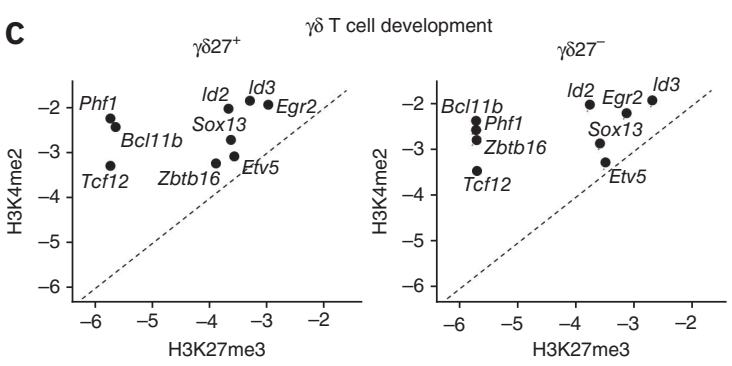

Figure 2 Peripheral $\gamma \delta 27^{+}$and $\gamma \delta 27^{-}$T cells display distinct genome-wide histone H3 methylation patterns. (a) ChIP-seq quantification of genes associated with differences in H3K4me2 or H3K27me3 histone modifications in the full gene or the proximal promoter region (as defined in Fig. 1a) in peripheral $\gamma \delta 27^{+}$and $\gamma \delta 27^{-} \mathrm{T}$ cells. (b) Histone-modification profiles of genes with a greater abundance of H3K4me2 or H3K27me3 in $\gamma \delta 27^{+}$or $\gamma \delta 27^{-} \mathrm{T}$ cells; the $5^{\prime}$ and $3^{\prime}$ ends are 'unscaled', and the remainder of the gene is rescaled to $2 \mathrm{~kb}$; long gray vertical lines correspond to gene regions along horizontal axes; gray shading indicates error bars. TSS, transcription start site. (c) Quantification ( $\log _{10}$-transformed) of H3K4me2 and H3K27me3 modifications of genes linked to T cell development (top) or of signature cytokine-encoding genes (bottom), in $\gamma \delta 27^{+}$or $\gamma \delta 27^{-} \mathrm{T}$ cells. Reproducibility and ChIP-qPCR, as in Figure 1. Data are from one experiment with cells pooled from eight mice.

the crosstalk between thymocytes and thymic epithelial cells and thus affects early T cell development ${ }^{27}$; Flt1, which binds vascular endothelial growh factor $\mathrm{A}$ and costimulates IFN- $\gamma$ production ${ }^{28}$; and OX40 (TNFRSF4), a costimulator of $\mathrm{CD}^{+}$and $\mathrm{CD} 8^{+} \mathrm{T}$ cells, as well as NK and NKT cells ${ }^{29}$, although its role in the activation of $\gamma \delta$ T cells remains unclear. The only chemokine receptor-encoding gene other than Ccr6 with substantially different modification in $\gamma \delta 27^{-} \mathrm{T}$ cells versus $\gamma \delta 27^{+} \mathrm{T}$ cells was Ccr1 (Supplementary Table 2); CCR1 has been linked to the migration of macrophages and neutrophils ${ }^{30}$ but not $\mathrm{T}$ cells.

Six of those eight candidates also had a difference in H3K4me2 modification in thymic $\gamma \delta 27^{-} \mathrm{T}$ cells versus $\gamma \delta 27^{+} \mathrm{T}$ cells (Supplementary Fig. 2). Except for Ccr1, those genes had a greater abundance of H3K4me 2 marks in peripheral $\gamma \delta$ T cell subsets than in thymic $\gamma \delta$ T cell subsets (Supplementary Fig. 2). This suggested that the epigenetic segregation of the gene-expression programs of $\gamma \delta 27^{-}$and $\gamma \delta 27^{+} \mathrm{T}$ cells starts in the thymus but is further consolidated as cells continue to mature in the periphery.

We did preliminary analysis of the expression of Dkk3 and Slamf 1 on $\gamma \delta$ T cells and assessed the effect of their deletion on the differentiation and function of $\gamma \delta$ T cells. $\gamma \delta 27^{-} \mathrm{T}$ cells showed considerable enrichment for $D k k 3$ mRNA and SLAMF1 protein relative to their abundance in $\gamma \delta 27^{+} \mathrm{T}$ cells (Fig. 3a,b). SLAMF1 was coexpressed with CCR6 in the thymus and in the periphery (Fig. 3b) and thus constitutes an additional marker for the CD27-CCR $6^{+} \gamma \delta$ T cell subset $^{10,13,14}$. Whereas we observed no difference between Slamf1-land wild-type mice in their production of IL-17, $D k k 3^{-/-}$mice displayed greater frequencies of peripheral IL-17-producing $\gamma \delta 27^{-}$ $\mathrm{T}$ cells than did wild-type mice (Fig. $3 c)$. In contrast, IL-17 expression was normal in $D k k 3^{-/-} \mathrm{T}_{\mathrm{H}} 17$ cells (Fig. $3 \mathbf{d}$ ), and IFN- $\gamma$ production was not altered in $D k k 3^{-1-} \gamma \delta 27^{+}$or $\mathrm{T}_{\mathrm{H}} 1$ cells (data not shown). These data suggested a role for DKK3 in selectively regulating IL-17 production in $\gamma \delta 27^{-} \mathrm{T}$ cells. Thus, this analysis has provided a set of potential additional regulators of the differentiation and activation of $\gamma \delta \mathrm{T}$ cells, some of which may also be shared with $\mathrm{CD} 4^{+}$helper T cells (Supplementary Table 2 ).

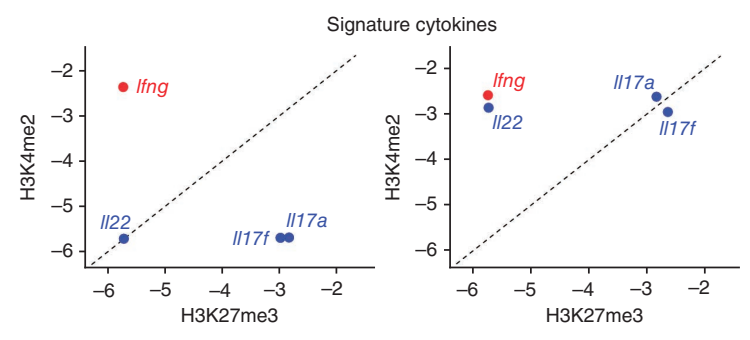

Epigenetic control of cytokine expression in $\gamma \delta \boldsymbol{\delta}$ cell subsets We next focused on the epigenetic regulation of genes encoding signature cytokines in the two $\gamma \delta \mathrm{T}$ cell subsets. In contrast to Il17a, IL17f and Il22 (Supplementary Table 2), Ifng did not show a difference in $\mathrm{H} 3$ methylation in $\gamma \delta 27^{+} \mathrm{T}$ cells versus $\gamma \delta 27^{-} \mathrm{T}$ cells (Supplementary Table 1). Individual ChIP-seq profiles showed that Il17a (Fig. 4a) and Il17f and Il22 (Supplementary Fig. 3a) accumulated many active H3K4me 2 marks in $\gamma \delta 27^{-} \mathrm{T}$ cells but not in $\gamma \delta 27^{+} \mathrm{T}$ cells, whereas the Ifng locus displayed $\mathrm{H} 3 \mathrm{~K} 4 \mathrm{me} 2$ marks in both $\gamma \delta$ cell subsets (Fig. 4a). ChIP followed by quantitative PCR (ChIP-qPCR) with primers for the respective promoters and other known regulatory conserved noncoding sequences ${ }^{31-33}$ confirmed accumulation of active $\mathrm{H} 3 \mathrm{~K} 4 \mathrm{me} 2$ marks in the Ifng locus in both $\gamma \delta 27^{+} \mathrm{T}$ cells and $\gamma \delta 27^{-} \mathrm{T}$ cells in the periphery (Fig. 4 b and Supplementary Fig. $\mathbf{3 b}, \mathbf{c}$ ) and in the thymus (Fig. 4c). The segregation of repressive H3K27me3 marks in $\gamma \delta 27^{+}$ $\mathrm{T}$ cells versus $\gamma \delta 27^{-} \mathrm{T}$ cells was less obvious at loci encoding the signature cytokines, by both ChIP-seq (Fig. 4a and Supplementary Fig. 3a) and ChIP-qPCR (Supplementary Fig. 4).

We also investigated additional histone modifications that associate with gene expression. Acetylation of histone $\mathrm{H} 3$ has been linked to the expression of genes important for the differentiation of helper T cells ${ }^{31,34}$. ChIP-qPCR of $\gamma \delta 27^{+}$and $\gamma \delta 27^{-} \mathrm{T}$ cells, with primers specific for the Ifng and $I l 17 a$ promoters, showed the presence of acetylated $\mathrm{H} 3$ marks at the Il17a locus exclusively in $\gamma \delta 27^{-}$cells, while these permissive marks were of almost identical abundance at the Ifng locus in both $\gamma \delta$ T cell subsets (Fig. $4 \mathbf{d}$ ).

To evaluate the effect of those histone-modification patterns on the expression of cytokine-encoding genes, we measured Ifng and Ill7a mRNA by reverse transcription followed by quantitative PCR (quantitative RT-PCR). Consistent with the epigenetic data, Il17a had $\sim 700$-fold higher expression in peripheral $\gamma \delta 27^{-} \mathrm{T}$ cells than in peripheral $\gamma \delta 27^{+}$T cells, while Ifng had $\sim 10$-fold higher expression in 
Figure 3 DKK3 and SLAMF1 are molecular determinants of $\gamma \delta 27^{-} \mathrm{T}$ cells. (a) Quantitative RT-PCR analysis of $D k k 3$ expression in ex vivo $\mathrm{CD}^{+}{ }^{+} \mathrm{T}$ cells (Naive splenic $\mathrm{CD} 4^{+}$), $\gamma \delta 27^{+}$ $T$ cells and $\gamma \delta 27^{-} T$ cells (sorted from peripheral organs) and $\mathrm{CD}^{+} \mathrm{T}_{\mathrm{H}} 1$ and $\mathrm{T}_{\mathrm{H}} 17$ cells generated in vitro (all sorted from C57BL/6 mice); results are presented relative to those of Actb (control gene). ${ }^{*} P<0.05$ (Mann-Whitney two-tailed test). (b) Surface expression of SLAMF1 (CD150), CD27 and CCR6 on total $\gamma \delta$ T cells from cutaneous lymph nodes (LN (cut); left) and thymus (right), assessed by flow cytometry. Numbers in quadrants indicate percent cells in each throughout. (c) Intracellular staining of IFN- $\gamma$ and IL-17A in $\gamma \delta 27^{-}$cells isolated from groups of C57BL/6 wild-type (WT), $D \mathrm{kk}^{-/-}$and Slamf1 ${ }^{-1-}$ mice (left), and frequency of $\mathrm{IL}-17^{+} \gamma \delta 27^{-} \mathrm{T}$ cells in those mouse strains (right). (d) Intracellular staining of IFN- $\gamma$ and IL-17A in $\mathrm{T}_{\mathrm{H}} 17$ cells differentiated in vitro from $\mathrm{CD} 4^{+} \mathrm{T}$ cells isolated from wild-type, $D \mathrm{kk}^{-/-}$and Slamf1 $1^{-1-}$ mice. Each symbol (a,c, right) represents an individual experiment. Data are from four experiments with cells pooled from four mice in each (a) or two (Slamf1 $\left.1^{--}\right)$, three $\left(\mathrm{Dkk}^{-\mathrm{I}^{-}}\right)$ or seven (wild-type) experiments with cells pooled from four mice in each (c) or are representative of three independent experiments with two or three mice in each (b) or two independent experiments with one mouse per strain in each (d).

$\gamma \delta 27^{+} \mathrm{T}$ cells than in $\gamma \delta 27^{-} \mathrm{T}$ cells (Fig. 4e). Moreover, Il17f and Il22 were also overexpressed in $\gamma \delta 27^{-} \mathrm{T}$ cells (Supplementary Fig. 3d). We also found similar differences for thymic $\gamma \delta$ T cell subsets, in which the difference in expression was $\sim 2$-fold for Ifng and $>200$-fold for $I l 17 a$ (Fig. 4f) and Il22 (data not shown). Of note, in the thymus, Ifng and Il17a transcripts were expressed only in $\gamma \delta$ T cells and were almost undetectable in $\alpha \beta$ thymocytes (Fig. 4f). Both Ifng and Il17a were expressed in $\mathrm{CD} 25^{+} \gamma \delta$ thymocytes, which represent a common progenitor population for both $\gamma \delta 27^{-}$and $\gamma \delta 27^{+} \mathrm{T}$ cells ${ }^{10}$, followed by further upregulation of Ifng in $\gamma \delta 27^{+} \mathrm{T}$ cells and of Il17a in $\gamma \delta 27^{-}$ thymocytes (Fig. 4f). These data demonstrated that the expression

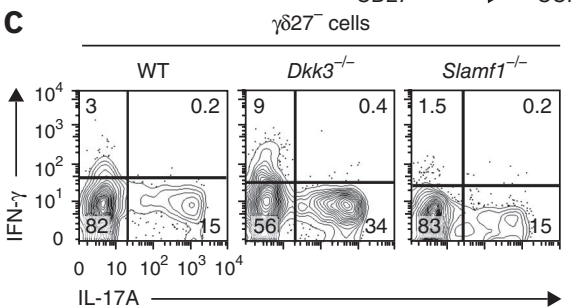

b
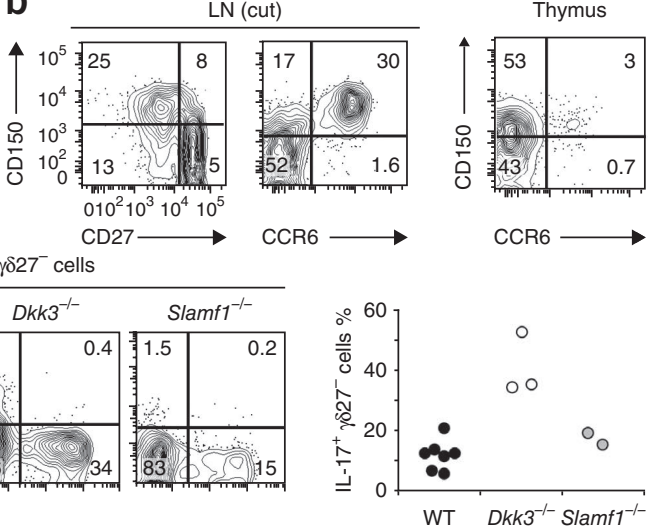

of genes encoding signature cytokines in $\gamma \delta \mathrm{T}$ cells is epigenetically patterned in the thymus and is sustained in peripheral $\gamma \delta \mathrm{T}$ cell subsets and revealed a distinct degree of polarization toward $\mathrm{T}_{\mathrm{H}} 1$-like or $\mathrm{T}_{\mathrm{H}} 17$-like effector function among $\gamma \delta \mathrm{T}$ cell subsets.

Epigenetic patterning of $T_{H} 1$ versus $T_{H} 17$ factors in $\gamma \delta \mathrm{T}$ cells We next analyzed our ChIP-seq data for (mostly transcription) factors that have been linked to the differentiation of $\mathrm{T}_{\mathrm{H}} 1$ or $\mathrm{T}_{\mathrm{H}} 17$ cells ${ }^{15}$

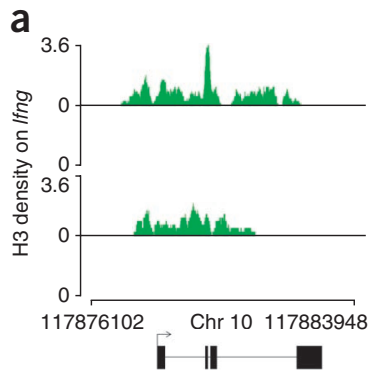

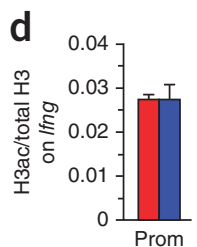

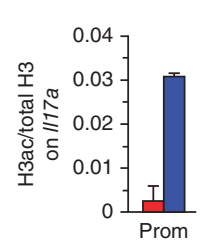

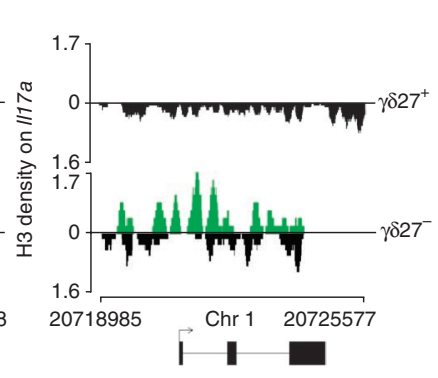

b

C
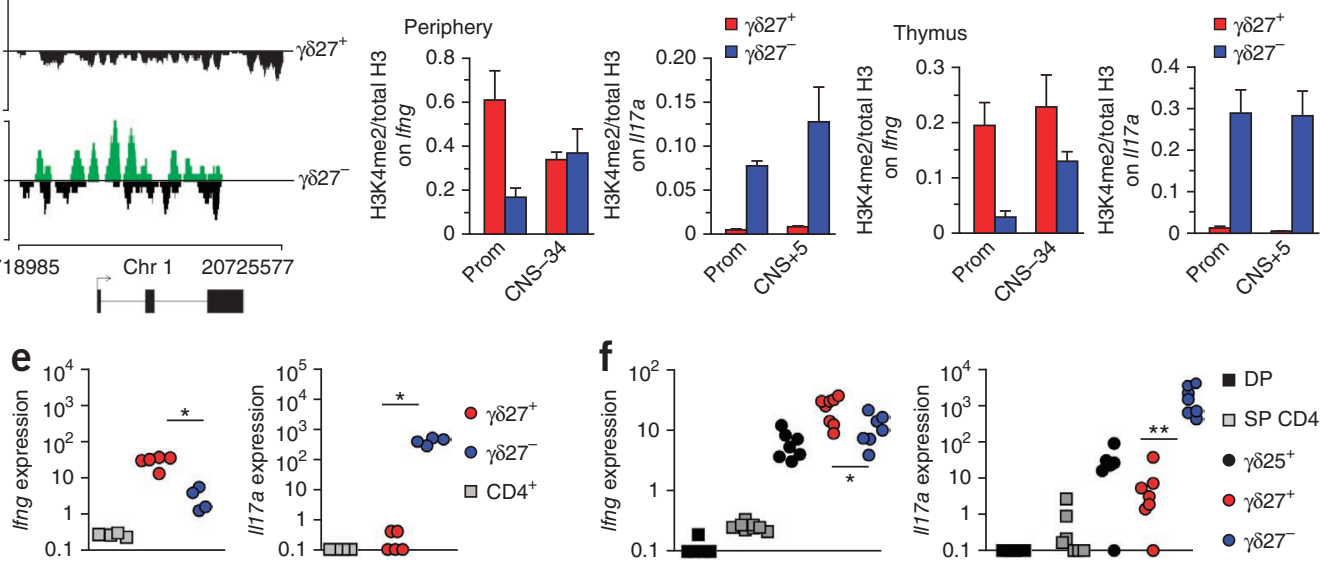

Figure 4 Epigenetic and transcriptional patterning of Ifng and //17a in $\gamma \delta \mathrm{T}$ cell subsets. (a) ChIP-seq analysis of H3K4me2 (green) and H3K27me3 (black) modifications on Ifng and $/ / 17 a$ in peripheral $\gamma \delta 27^{+}$and $\gamma \delta 27^{-}$T cells; below, chromosome (Chr) locations and exon positions (black boxes). (b,c) ChIP-qPCR analysis of H3K4me2 modifications on Ifng (promoter (Prom) and conserved noncoding sequence -34 regions (CNS-34)) and /I17a (promoter (Prom) and conserved noncoding sequence +5 regions $(C N S+5)$ ) in peripheral (b) or thymic (c) $\gamma \delta 27^{+}$and $\gamma \delta 27^{-}$T cells; results are presented relative to total H3. (d) ChIP-qPCR analysis of total acetylated histone H3 in the promoter regions of Ifng or IL $17 a$ in peripheral $\gamma \delta 27^{+}$and $\gamma \delta 27^{-}$ T cells (presented as in c). (e) Quantitative RT-PCR analysis of the expression of Ifng and $/ / 17 a$ in $\mathrm{CD}^{+}, \gamma \delta 27^{+}$and $\gamma \delta 27^{-} \mathrm{T}$ cells from pooled spleen and lymph nodes of C57BL/6 mice (e) and in $\mathrm{CD} 4^{+} \mathrm{CD} 8^{+}$double-positive (DP) and CD4+ single-positive (SP CD4) thymocytes of the $\alpha \beta$ T cell lineage and $\mathrm{CD} 25^{+} \mathrm{CD} 27^{+}\left(\gamma \delta 25^{+}\right), \mathrm{CD} 25^{-} \gamma \delta 27^{+}$and $\mathrm{CD} 25^{-} \gamma \delta 27^{-}$thymocytes of the $\gamma \delta \mathrm{T}$ cell lineage (e), presented relative to Actb expression. Each symbol $\left(\right.$ e,f) represents an individual experiment. ${ }^{*} P<0.05$ and ${ }^{*} P<0.001$ (Mann-Whitney two-tailed test). Data are from one experiment with cells pooled from eight mice ( $\mathbf{a}-\mathbf{d})$ or eight independent experiments with cells pooled from four mice in each (e,f; mean and s.d. in $\mathbf{b}-\mathbf{d})$. 


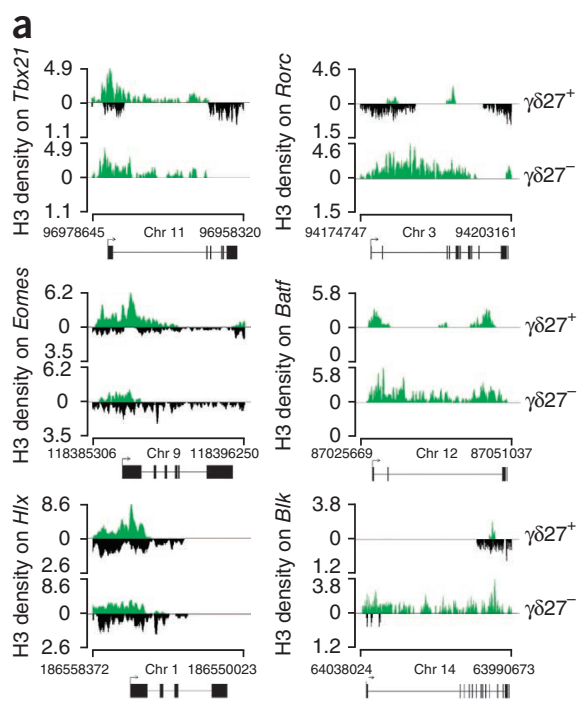

Figure 5 Permissive histone $\mathrm{H} 3$ methylation patterns associate with transcription of $\mathrm{T}_{\mathrm{H}} 1$ and $\mathrm{T}_{\mathrm{H}}$ 17-related factors in $\gamma \delta \mathrm{T}$ cell subsets. (a) ChIP-seq analysis of H3K4me2 (green) and H3K27me3 (black) modifications on genes encoding $T_{H} 1$-related factors ( $T b \times 21$, Eomes, $H / x$; left) and $\mathrm{T}_{\mathrm{H}} 17$-related factors (Rorc, Batf, Blk; right) in peripheral $\gamma \delta 27^{+}$ and $\gamma \delta 27^{-}$T cells (below plots, as in Fig. 4a). (b) Quantification (log $10^{-t r a n s f o r m e d) ~ o f ~ g e n e-s p e c i f i c ~} \mathrm{H} 3 \mathrm{~K} 4 \mathrm{me} 2 \mathrm{modifications}$ on genes in $\gamma \delta 27^{+} \mathrm{T}$ cells and $\gamma \delta 27^{-} \mathrm{T}$ cells for genes grouped as $\mathrm{T}_{\mathrm{H}} 1$ - and $\mathrm{T}_{\mathrm{H}} 17$-related factors (top left), genes linked to $\gamma \delta \mathrm{T}$ cell development (top right), genes associated with alternative effector cell types (bottom left) and housekeeping reference or survival genes (bottom right). (c) ChIP-qPCR analysis of H3K36me3 modifications on Tbx21, Eomes, and Rorc in $\gamma \delta 27^{+}$and $\gamma \delta 27^{-} \mathrm{T}$ cells, presented relative to the abundance of total H3. (d) Quantitative RT-PCR analysis of genes encoding $\mathrm{T}_{\mathrm{H}} 1$-related factors (top) and $\mathrm{T}_{\mathrm{H}} 17$-related factors (bottom) on ex vivo $\mathrm{CD}^{+}{ }^{+} \mathrm{T}$ cells and $\gamma \delta 27^{+}$and $\gamma \delta 27-\mathrm{T}$ cells (derived from peripheral $\mathrm{T}$ cells) and $\mathrm{CD} 4{ }^{+} \mathrm{T}_{\mathrm{H}} 1$ and $\mathrm{T}_{\mathrm{H}} 17$ cells generated in vitro, presented relative to Actb expression. $\mathrm{NS}$, non significant; ${ }^{*}<<0.05$ (Mann-

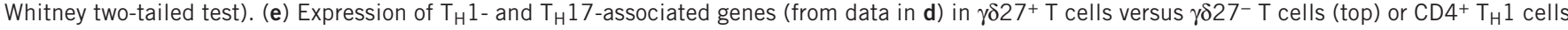
versus $T_{H} 17$ cells (bottom). Each symbol (d,e) represents an individual experiment (d) or the mean of the data in $\mathbf{d}$ (e). Data are from one experiment with cells pooled from eight mice $(\mathbf{a}-\mathbf{c})$ or five independent experiments with cells pooled from four mice in each (d,e; mean and s.d. in $\mathbf{c}, \mathbf{e})$. or, in some instances, specifically to the differentiation of cytokineproducing $\gamma \delta \mathrm{T}$ cells $\mathrm{s}^{35,36}$. For simplicity, here we have designated the regulators of IFN- $\gamma$ or IL-17 production (in either $\mathrm{CD} 4^{+}$or $\gamma \delta$ $\mathrm{T}$ cells) ' $\mathrm{T}_{\mathrm{H}} 1$ factors' or ' $\mathrm{T}_{\mathrm{H}} 17$ factors', respectively. Examination of individual ChIP-seq profiles (Fig. 5a) or their global activity (Fig. 5b) revealed $\mathrm{T}_{\mathrm{H}} 17$ polarization of $\gamma \delta 27^{-} \mathrm{T}$ cells but not of $\gamma \delta 27^{+}$ $\mathrm{T}$ cells, indicated by the accumulation of permissive H3K4me 2 marks in genes encoding differentiation factors, such as Rorc, Rora or Batf (Fig. 5a,b), as well as in the cytokine receptor-encoding genes Illr 1 and Il23r $r^{1,20}$ and the chemokine receptor-encoding gene Ccr6 (ref. 13) (Supplementary Fig. 5a). Moreover, Rorc and Blk (Fig. 5a) and Maf and Irf4 (data not shown) displayed repressive H3K27me3 modifications in $\gamma \delta 27^{+} \mathrm{T}$ cells but not in $\gamma \delta 27^{-} \mathrm{T}$ cells. In contrast, most genes encoding $\mathrm{T}_{\mathrm{H}} 1$-differentiation factors (such as Tbx21, Eomes and $H l x$ ) were positively marked by $\mathrm{H} 3 \mathrm{~K} 4 \mathrm{me} 2$ in both $\gamma \delta$ $\mathrm{T}$ cell subsets, and some (Eomes and $H l x$ ) also displayed substantial repressive H3K27me3 modification in both $\gamma \delta$ T cell subsets (Fig. 5a). As reference, genes encoding molecules associated with cell survival, the development of $\gamma \delta$ T cells or alternative T cell effector functions did not show a difference in $\mathrm{H} 3$ modification in the two $\gamma \delta \mathrm{T}$ cell subsets (Fig. 5b and data not shown).

To further document the epigenetic regulation of important transcription regulators in $\gamma \delta$ T cell subsets, we analyzed the H3K36me 3 marking of the Tbx21, Eomes and Rorc loci. H3K36me3 modifications, which accumulate at the $3^{\prime}$ end of genes, correlate with transcriptional activity in intron-containing genes ${ }^{37}$. The two $\gamma \delta$ T cell subsets showed a difference of less than threefold in the H3K36me3 marking of Tbx21 or Eomes, whereas the Rorc locus had more than tenfold more H3K36me3 marking in $\gamma \delta 27^{-} \mathrm{T}$ cells than in $\gamma \delta 27^{+} \mathrm{T}$ cells (Fig. $\mathbf{5 c}$ ). The difference in the patterning of $\mathrm{T}_{\mathrm{H}} 1$ or $\mathrm{T}_{\mathrm{H}} 17$ factors in peripheral $\gamma \delta \mathrm{T}$ cell subsets extended to the transcriptional level, as by quantitative RT-PCR analysis we estimated the abundance of Rorc transcripts was $\sim 600$-fold greater in $\gamma \delta 27^{-} \mathrm{T}$ cells than in $\gamma \delta 27^{+} \mathrm{T}$ cells, whereas the abundance of Tbx21 and Eomes was only slightly (four- to sixfold) greater in $\gamma \delta 27^{+} \mathrm{T}$ cells (Fig. 5d). Furthermore, H3K4me2 modifications of the Ifng promoter in $\gamma \delta 27^{+} \mathrm{T}$ cells were similar in wild-type and $T b \times 21^{-1-}$ mice (Supplementary Fig. 6), and Tbx $21^{-1-}$ mice had a substantial proportion of IFN- $\gamma$-producing $\gamma \delta$ T cells (Supplementary Fig. 7a,b). In contrast, $\operatorname{Rorc}^{-1-}$ mice lacked the CCR6 ${ }^{+}\left(\gamma \delta 27^{-}\right) \mathrm{T}$ cell subset in both the thymus and spleen (Supplementary Fig. 7c) and did not express IL-17A in total $\gamma \delta \mathrm{T}$ cells (Supplementary Fig. 7d).

Although the expression of many $\mathrm{T}_{\mathrm{H}} 1$ factors versus that of $\mathrm{T}_{\mathrm{H}} 17$ factors segregated with the two peripheral $\gamma \delta \mathrm{T}$ cell subsets (Fig. 5e), the transcriptional polarization was much stronger for the $\mathrm{T}_{\mathrm{H}} 17$ program (Fig. 5d,e). That was consistent with the accumulation of repressive $\mathrm{H} 3 \mathrm{~K} 27 \mathrm{me} 3$ marks at $\mathrm{T}_{\mathrm{H}} 17$-related loci, such as Rorc, Blk and Maf (Fig. 5a and data not shown), in $\gamma \delta 27^{+} \mathrm{T}$ cells. Of note, the expression of Rorc, Rora and Maf was higher in $\gamma \delta 27^{-}$T cells ex vivo than in $\mathrm{T}_{\mathrm{H}} 17$ cells generated in vitro (Fig. 5d), and overall there was better segregation of $\mathrm{T}_{\mathrm{H}} 17$ transcription factors in $\gamma \delta \mathrm{T}$ cells than in $\mathrm{CD}^{+}$helper 
Figure 6 Differentiation of IL-17+IFN- $\gamma^{+}$ $\gamma \delta 27-$ cells in vitro and in vivo.

(a) Intracellular staining of IFN- $\gamma$ and IL-17A in $\gamma \delta 27^{+}$and $\gamma \delta 27^{-} T$ cells isolated from pooled spleen and lymph nodes and stimulated in vitro for $48 \mathrm{~h}$ in the presence of IL-1 $\beta$ plus IL-23 or standard $T_{H} 1$ - or $T_{H} 17$ polarizing conditions. ND, not determined (lack of cell viability; Supplementary Fig. 8). (b) Frequency of IL-17A+IFN- $\gamma^{+}$cells in the cultures in a, normalized to the proportion of live cells (Supplementary Fig. 8).

(c) Intracellular IFN- $\gamma$ and IL-17A (right) in total $\gamma \delta$ T cells (gated at left) from peritoneal exudates obtained at 2 or 6 weeks of the development of ID8 tumors in C57BL/6 mice. Numbers adjacent to outlined areas indicate percent $\gamma \delta$ T cells (right column), or IFN- $\gamma^{+} \gamma \delta$ T cells (top left), IL-17A+ $\gamma \delta$ T cells (bottom right) or IFN- $\gamma^{+}$IL- $17 A^{+} \gamma \delta$ T cells (top right; all left column). (d) Overlay of the surface staining of CD27 on IL-17A+, IL-17A+IFN- $\gamma^{+}$ or IFN- $\gamma^{+} \gamma \delta$ T cells from peritoneal exudates at 6 weeks of ID8 tumor development (as in c). (e) Frequency of IL-17A IFN- $\gamma^{+}$ cells among CD27- $\gamma \delta$ T cells (as in $\mathbf{c}, \mathbf{d}$ ).

Each symbol (b,e) represents an individual experiment. ${ }^{*} P<0.05$ and ${ }^{* *} P<0.01$ (Mann-Whitney two-tailed test). Data are representative of four to six independent experiments $(\mathbf{a}, \mathbf{b})$ or two independent experiments with four mice in each (c-e).
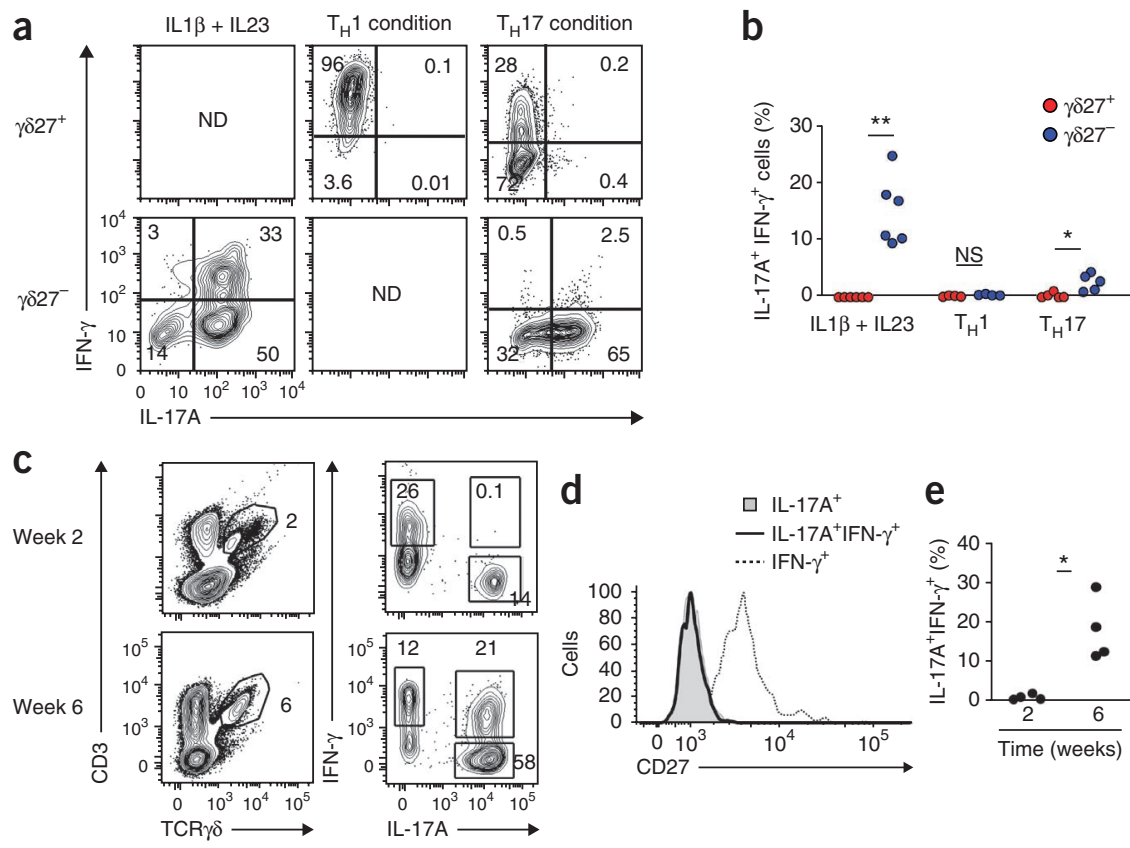

d
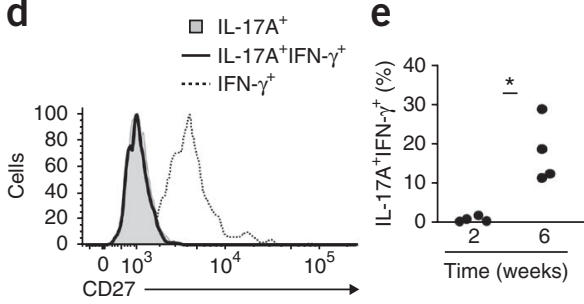

T cell subsets (Fig. 5e). These data documented distinct epigenetic patterning and transcriptional regulation of $\mathrm{T}_{\mathrm{H}} 1$ factors versus $\mathrm{T}_{\mathrm{H}} 17$ factors in $\gamma \delta$ T cell subsets and showed that both $\gamma \delta 27^{+}$and $\gamma \delta 27^{-}$ $\mathrm{T}$ cells had $\mathrm{T}_{\mathrm{H}} 1$ factors epigenetically primed for expression.

\section{Stable versus plastic differentiation of $\gamma \delta$ T cell subsets}

In line with the epigenetic status of Ifng and the genes encoding $\mathrm{T}_{\mathrm{H}} 1$ factors described above, $\gamma \delta 27^{-} \mathrm{T}$ cells stimulated in vitro are reported to produce both IL-17 and IFN- $\gamma^{10}$. To further explore the conditions that trigger IFN- $\gamma$ production in those cells, we established short-term cultures of highly purified $\gamma \delta 27^{-}$or $\gamma \delta 27^{+} \mathrm{T}$ cells in cytokine-defined media. $\gamma \delta 27^{-}$T cells responded to IL- $1 \beta$ and IL- 23 by acquiring IFN- $\gamma$ production, which resulted in a sizeable population of cells that produced both IL-17 and IFN- $\gamma$ (Fig. 6a,b). The differentiation of $\gamma \delta 27^{-}$T cells into cells that produced both IL-17 and IFN- $\gamma$ was negligible under $\mathrm{T}_{\mathrm{H}}$ 17-differentiation conditions (Fig. 6a,b), whereas $\mathrm{T}_{\mathrm{H}} 1$-differentiation conditions did not support the survival of $\gamma \delta 27^{-}$ T cells (Supplementary Fig. 8). Furthermore, $\gamma \delta 27^{+} \mathrm{T}$ cells stably and exclusively produced IFN- $\gamma$, even under $\mathrm{T}_{\mathrm{H}} 17$ conditions (Fig. 6a). Of note, stimulation with IL-1 $\beta$ and IL-23 resulted in the death of $\gamma \delta 27^{+}$ cells (Supplementary Fig. 8), consistent with their lack of expression of the corresponding receptors (Supplementary Fig. 5).

Finally, we sought to determine if the plasticity of $\gamma \delta 27^{-}$ $\mathrm{T}$ cells was detectable in vivo. To investigate whether the systemic immune response to infection could drive the differentiation of IL-17 ${ }^{+} \mathrm{IFN}-\gamma^{+} \gamma \delta \mathrm{T}$ cells, we set up in vivo infection models based on four distinct types of microorganisms that elicit $\gamma \delta \mathrm{T}$ cell responses ${ }^{10,20}$ : a parasite (Plasmodium berghei), a virus (murid herpes virus 4), a bacterium (Mycobacterium avium) and a fungus (Candida albicans). We isolated cells from the spleen and lymph nodes at the peak of each $\gamma \delta$ T cell response. However, we did not observe substantial populations of IL- $17^{+} \mathrm{IFN}-\gamma^{+} \gamma \delta$ T cells in these acute infection models (Supplementary Fig. 9).

We reasoned that a strong local inflammatory response might be necessary for the differentiation of IL- $17^{+} \mathrm{IFN}-\gamma^{+} \gamma \delta \mathrm{T}$ cells in vivo.
We therefore transplanted an ovarian cancer cell line (ID8) known to produce a highly inflammatory microenvironment ${ }^{38}$ into the peritoneal cavity of mice and monitored the growth of ID8 tumor cells (transfected with a plasmid bearing a luciferase reporter-encoding gene) by bioimaging techniques ${ }^{38}$ (data not shown). We observed the accumulation of a sizeable population of IL- $17^{+} \mathrm{IFN}-\gamma^{+} \gamma \delta$ T cells after tumor growth (at 6 weeks; Fig. 6c). Those IL-17 IFN- $\gamma^{+}$T cells were CD27- ${ }^{-}$, unlike the IFN- $\gamma^{+} \gamma \delta$ T cells (Fig. 6d). In fact, IL-17+IFN- $\gamma^{+}$ cells constituted up to $30 \%$ of the $\gamma \delta 27^{-}$T cell subset present in the tumor-bearing peritoneal cavity (Fig. 6e). In contrast, $\gamma \delta 27^{+} \mathrm{T}$ cells remained exclusive producers of IFN- $\gamma$ (Fig. 6d). These data demonstrated that the plasticity of $\gamma \delta 27^{-} \mathrm{T}$ cells, which is in contrast to the stable phenotype of the $\gamma \delta 27^{+} \mathrm{T}$ cells, was triggered under specific local inflammatory conditions and may thus contribute to their function in vivo.

\section{DISCUSSION}

Epigenetic mechanisms ensure the autonomous maintenance of lineage phenotype in differentiated cells, even through mitotic divisions. Methylation patterns of active $\mathrm{H} 3 \mathrm{~K} 4$ and repressive $\mathrm{H} 3 \mathrm{~K} 27$ have been shown to affect the functional (in)stability of effector $\mathrm{CD} 4^{+}$helper $\mathrm{T}$ cell subsets ${ }^{18,32,39}$. Here we have described the epigenetic landscape of $\mathrm{T}_{\mathrm{H}} 1$ - and $\mathrm{T}_{\mathrm{H}} 17$-related loci in $\gamma \delta \mathrm{T}$ cells freshly isolated from lymphoid organs. Through the use of genome-wide ChIP-seq analysis, we have identified many potential previously unknown participants in the differentiation and activation of $\gamma \delta$ T cell subsets. Notably, among the top genes selected on the basis of their differences in histone $\mathrm{H} 3$ marking in $\gamma \delta 27^{+}$versus $\gamma \delta 27^{-} \mathrm{T}$ cell subsets, only a minority (40 of 120) were also different in $C D 4^{+} \mathrm{T}_{\mathrm{H}} 1$ versus $\mathrm{T}_{\mathrm{H}} 17$ subsets. This suggested that different lineage-specific mechanisms of differentiation might operate in $\gamma \delta \mathrm{T}$ cells, as exemplified by DKK3.

DKK3 is a secreted glycoprotein that modulates Wnt signaling and whose expression is often epigenetically silenced in a variety of cancer cell types, which suggests a potential role as a tumor suppressor ${ }^{40}$. Although little is known about the functions of DKK3 in the immune 
system, it is reported to have a powerful regulatory function in $\mathrm{CD}^{+}$ $\mathrm{T}$ cells ${ }^{23}$. DKK3 is expressed in transgenic CD $8^{+} \mathrm{T}$ cells tolerized in the neonatal period through interactions with a self antigen expressed in keratinocytes (in a double-transgenic mouse model) and is necessary and sufficient for maintenance of $\mathrm{CD}^{+} \mathrm{T}$ cell tolerance in this model. In particular, $D k k 3^{-/-}$mice reject autologous skin grafts and readily eradicate transplantable tumors ${ }^{23}$. Notably, published studies have suggested a general absence of $D k k 3$ expression on T cell subsets, except for a specific subset of long-term memory CD8 ${ }^{+} \mathrm{T}$ cells ${ }^{41}$. Our findings have extended $D k k 3$ expression to the $\gamma \delta 27^{-}$T cell subset while excluding it from $\gamma \delta 27^{+} \mathrm{T}$ cells and $\mathrm{CD} 4^{+}$helper $\mathrm{T}$ subsets. Furthermore, $D k k 3^{-1-} \gamma \delta 27^{-} \mathrm{T}$ cell populations showed enrichment for cells that produced IL-17, which selectively linked DKK3 to the functional differentiation of this $\gamma \delta \mathrm{T}$ cell subset.

Although the mechanisms of action of DKK3 remain unclear, it is widely regarded as an inhibitor of the Wnt signaling cascade ${ }^{40}$. Notably, the downstream (transcriptional) effectors of Wnt signaling, TCF1 and Lef, have been shown to inhibit the differentiation of IL-17-producing $\gamma \delta \mathrm{T}$ cells ${ }^{42}$. Moreover, in our ChIP-seq analyses, Tcf7 (which encodes TCF1) and Lef were biased toward $\gamma \delta 27^{+} \mathrm{T}$ cells (albeit below the eightfold threshold that was the inclusive criteria we used here): Lef1 displayed a 6.4-fold enrichment for active H3K4me2 marks in $\gamma \delta 27^{+} \mathrm{T}$ cells and 4.8-fold enrichment for repressive H3K27me3 marks in $\gamma \delta 27^{-} \mathrm{T}$ cells; and Tcf7 showed a 4.5 -fold accumulation of H3K27me3 marks in $\gamma \delta 27^{-} \mathrm{T}$ cells. Given the increased production of IL-17 by $D k k 3^{-1-} \gamma \delta 27^{-}$T cells, these data suggested crosstalk between DKK 3 and Wnt signaling during the differentiation of $\gamma \delta$ T cells that warrants further investigation.

As functional differentiation of $\gamma \delta \mathrm{T}$ cells can occur in the thymus ${ }^{10-12}$, the stability of cellular phenotypes in the periphery probably depends on the epigenetic patterning of key (master) transcription factors. Our data showed that Tbx21 and Eomes (which encode $\mathrm{T}_{\mathrm{H}} 1$-related transcription factors) and Rorc and Batf (which encode $\mathrm{T}_{\mathrm{H}} 17$-related transcription factors) were distinctively patterned (by histone $\mathrm{H} 3$ modifications) in the $\gamma \delta 27^{+}$versus $\gamma \delta 27^{-}$subsets, and this was associated with their mRNA expression. Notably, genetic deletion of Tbx21 or Rorc (data not shown) did not impair the epigenetic marking of the respective signature cytokine-encoding genes Ifng and Il17. That was consistent with studies showing that T-bet (encoded by $T b \times 21$ ) has very modest effect on the active enhancer repertoire of $\mathrm{CD}^{+} \mathrm{T}_{\mathrm{H}} 1$ cells ${ }^{43}$. That result notwithstanding, our data cannot exclude the possibility that histone patterning of Ifng or Il17 in $\gamma \delta \mathrm{T}$ cell subsets is controlled by unknown combinations of $\mathrm{T}_{\mathrm{H}} 1$ or $\mathrm{T}_{\mathrm{H}} 17$-related transcriptional regulators. Of note, members of the STAT family of transcription factors have a critical role in shaping the epigenetic landscape of $\mathrm{T}_{\mathrm{H}} 1, \mathrm{~T}_{\mathrm{H}} 2$ and $\mathrm{T}_{\mathrm{H}} 17$ cells ${ }^{18,43,44}$. Although the role of STAT1 and STAT4 in the differentiation of IFN- $\gamma^{+} \gamma \delta$ $\mathrm{T}$ cells requires further investigation, STAT3 is largely dispensable for the generation of IL-17-producing $\gamma \delta \mathrm{T}$ cells ${ }^{45}$. That is consistent with their independence of IL- 6 signals ${ }^{46}$ and illustrates how the developmental programming of $\gamma \delta \mathrm{T}$ cells (in the thymus) follows rules distinct from those of $\mathrm{CD} 4^{+} \mathrm{T}$ cell differentiation after activation (by signaling via the $\mathrm{T}$ cell antigen receptor and cytokines) in the periphery.

While our study here concentrated on intracellular (nuclear) mechanisms of differentiation, it is also important to consider the roles of extracellular cues. In particular, the innate cytokines IL-1 $\beta$ and IL-23 drive the selective population expansion of $\mathrm{IL}-17^{+} \gamma \delta$ $\mathrm{T}$ cells in infection ${ }^{20}$, autoimmunity ${ }^{1}$ and tumor ${ }^{47}$ models. Our data showed selective epigenetic and transcriptional polarization of IL-1R1 and IL-23R in $\gamma \delta 27^{-} \mathrm{T}$ cells, which highlights the importance of these receptors in the biology of IL- $17^{+} \gamma \delta$ T cells (but not IFN- $\gamma^{+} \gamma \delta$ T cells). IL-1 $\beta$ and IL-23 also seemed to be key elements of the inflammatory milieu that triggered the plasticity of $\gamma \delta 27^{-} \mathrm{T}$ cell in vitro. In vivo, we detected that plasticity in the tumor microenvironment but not during systemic responses to infection. Notably, CD $4^{+} \mathrm{T}$ cells 'convert' from $\mathrm{T}_{\mathrm{H}} 17$ cells to $\mathrm{T}_{\mathrm{H}} 1$ cells under IL-23-dependent inflammatory conditions in experimental autoimmune encephalomyelitis but not during acute cutaneous infection with Candida albicans, while in the same conditions, $\gamma \delta$ T cells remain producers of IL-17 and do not acquire IFN- $\gamma$ expression ${ }^{48}$. However, that does not indicate that microorganisms cannot trigger plasticity in $\gamma \delta 27^{-} \mathrm{T}$ cell, as it has been observed in gut-associated (mesenteric) lymph nodes after oral infection with Listeria $^{49}$. Instead, we think this highlights the importance of the local inflammatory environment for the acquisition of IFN- $\gamma$ expression by $\gamma \delta 27^{-} \mathrm{T}$ cells.

The epigenomic data on $\gamma \delta \mathrm{T}$ cell subsets presented here provides a framework for the analysis and interpretation of the functions of $\gamma \delta 27^{+}$and $\gamma \delta 27^{-} \mathrm{T}$ cells in the periphery. In particular, we found that $\gamma \delta 27^{-} \mathrm{T}$ cells that acquired the ability to produce IL-17 during thymic development were nonetheless endowed with functional plasticity that allowed them to also produce IFN- $\gamma$ under local inflammatory conditions. Future studies should determine the specific roles of IL- $17^{+}$IFN- $\gamma^{+} \gamma \delta$ cells in vivo models of infection, cancer or autoimmunity. These cells have been observed in the central nervous system of mice suffering experimental autoimmune encephalomyelitis (but not in healthy control mice) ${ }^{50}$ and may thus contribute to the pathogenic role of $\gamma \delta$ T cells in this ${ }^{1}$ and other disease models.

\section{METHODS}

Methods and any associated references are available in the online version of the paper.

\section{Accession codes. GEO: ChIP-seq data, GSE42098.}

Note: Any Supplementary Information and Source Data files are available in the online version of the paper.

\section{ACKNOWLEDGMENTS}

We thank V. Benes for technical assistance with the ChIP-seq experiments; J. Ribot, S. de Almeida and N. Gonçalves-Sousa for technical advice; H. Kulbe, F. Balkwill and R. Thompson for help with the ID8 tumor model; M.J. Nunes and E. Rodrigues for help with ChIP procedures; and M. Soares, A. Vieira and S. Marques for help with cell sorting; A. Hayday, L. Lefrançois and M. Saraiva for discussions; B. Arnold and C. Niehrs (Deutsches Krebsforschungszentrum, Heidelberg) for Dkk3-deficient mice; C. Terhorst and B. van Driel (Harvard Medical School) for Slamf1-deficient mice; K. Roby (University of Kansas) for ID8 ovarian cancer cells; A. Pamplona (Instituto de Medicina Molecular) for Plasmodium berghei ANKA with transgenic expression of GFP; P. Simas (Instituto de Medicina Molecular) for murid herpes virus 4; M. Correia-Neves (Universidade do Minho) for Mycobacterium avium strain 244.; C. Reis e Sousa (The London Research Institute) for Candida albicans yeast strain WT-SC 3314; and the staff of the animal and flow cytometry facilities of our institutes for experimental assistance. Supported by the European Research Council (StG_260352 to B.S.-S.), the Wellcome Trust (D.J.P.), the European Molecular Biology Organization (B.S.-S.), Fundação para a Ciência e Tecnologia (K.S., A.R.G. and M.R.) and the Graduate Program in Areas of Basic and Applied Biology of Universidade do Porto (M.R.).

\section{AUTHOR CONTRIBUTIONS}

N.S. planned and did experiments in Figures 1, 2, 4 and 5; K.S. planned and did experiments in Figures 3-6; A.R.G. planned and did experiments in Figures 1 and 2; M.R. planned and did experiments in Figure 6; A.Q.G. planned and did experiments in Figures 4 and 5; D.J.P. contributed to designing the study and writing the manuscript; A.Q.G. helped to design and supervise the study; and B.S.-S. designed and supervised the study and wrote the manuscript.

\section{COMPETING FINANCIAL INTERESTS}

The authors declare no competing financial interests. 
Reprints and permissions information is available online at http://www.nature.com/ reprints/index.html.

1. Sutton, C.E. et al. Interleukin-1 and IL-23 induce innate IL-17 production from $\gamma \delta$ $\mathrm{T}$ cells, amplifying Th17 responses and autoimmunity. Immunity 31, 331-341 (2009).

2. Petermann, F. et al. $\gamma \delta \mathrm{T}$ cells enhance autoimmunity by restraining regulatory T cell responses via an interleukin-23-dependent mechanism. Immunity 33, 351-363 (2010).

3. Pantelyushin, S. et al. Roryt+ innate lymphocytes and $\gamma \delta$ T cells initiate psoriasiform plaque formation in mice. J. Clin. Invest. 122, 2252-2256 (2012).

4. Shichita, T. et al. Pivotal role of cerebral interleukin-17-producing $\gamma \delta T$ cells in the delayed phase of ischemic brain injury. Nat. Med. 15, 946-950 (2009).

5. Cai, Y. et al. Pivotal role of dermal IL-17-producing $\gamma \delta$ T cells in skin inflammation. Immunity 35, 596-610 (2011)

6. Lockhart, E., Green, A.M. \& Flynn, J.L. IL-17 production is dominated by $\gamma \delta$ T cells rather than CD4 T cells during Mycobacterium tuberculosis infection. J. Immunol. 177, 4662-4669 (2006).

7. Bonneville, M., O'Brien, R.L. \& Born, W.K. $\gamma \delta$ T cell effector functions: a blend of innate programming and acquired plasticity. Nat. Rev. Immunol. 10, 467-478 (2010).

8. Yin, Z. et al. T-Bet expression and failure of GATA-3 cross-regulation lead to default production of IFN- $\gamma$ by $\gamma \delta$ T cells. J. Immunol. 168, 1566-1571 (2002).

9. Gomes, A.Q., Martins, D.S. \& Silva-Santos, B. Targeting $\gamma \delta T$ lymphocytes for cancer immunotherapy: from novel mechanistic insight to clinical application. Cancer Res. 70, 10024-10027 (2010).

10. Ribot, J.C. et al. CD27 is a thymic determinant of the balance between interferon$\gamma$ - and interleukin 17-producing $\gamma \delta \mathrm{T}$ cell subsets. Nat. Immunol. 10, 427-436 (2009).

11. Jensen, K.D. et al. Thymic selection determines $\gamma \delta$ T cell effector fate: antigen-naive cells make interleukin-17 and antigen-experienced cells make interferon $\gamma$. Immunity 29, 90-100 (2008).

12. Shibata, K. et al. Identification of $\mathrm{CD}_{2} 5^{+} \gamma \delta$ T cells as fetal thymus-derived naturally occurring IL-17 producers. J. Immunol. 181, 5940-5947 (2008).

13. Haas, J.D. et al. CCR6 and NK1.1 distinguish between IL-17A and IFN- $\gamma$-producing $\gamma \delta$ effector T cells. Eur. J. Immunol. 39, 3488-3497 (2009).

14. Martin, B., Hirota, K., Cua, D.J., Stockinger, B. \& Veldhoen, M. Interleukin17-producing $\gamma \delta \mathrm{T}$ cells selectively expand in response to pathogen products and environmental signals. Immunity 31, 321-330 (2009).

15. Zhu, J., Yamane, H. \& Paul, W.E. Differentiation of effector CD4 T cell populations. Annu. Rev. Immunol. 28, 445-489 (2010).

16. Haas, J.D. et al. IL-17-mediated negative feedback restricts development of IL-17producing $\gamma \delta$ T cells to an embryonic wave. Immunity 37, 48-59 (2012).

17. Narayan, K. et al. Intrathymic programming of effector fates in three molecularly distinct $\gamma \delta$ T cell subtypes. Nat. Immunol. 13, 511-518 (2012).

18. Wei, G. et al. Global mapping of $\mathrm{H} 3 \mathrm{~K} 4 \mathrm{me} 3$ and $\mathrm{H} 3 \mathrm{~K} 27 \mathrm{me} 3$ reveals specificity and plasticity in lineage fate determination of differentiating $\mathrm{CD}^{+}{ }^{+} \mathrm{T}$ cells. Immunity 30, 155-167 (2009)

19. Hirahara, K. et al. Helper T-cell differentiation and plasticity: insights from epigenetics. Immunology 134, 235-245 (2011).

20. Ribot, J.C. et al. Cutting edge: adaptive versus innate receptor signals selectively control the pool sizes of murine IFN- $\gamma$ - or IL-17-producing $\gamma \delta$ T cells upon infection. J. Immunol. 185, 6421-6425 (2010).

21. Randall, K.L. et al. DOCK8 deficiency impairs CD8 T cell survival and function in humans and mice. J. Exp. Med. 208, 2305-2320 (2011).

22. Jabara, H.H. et al. DOCK8 functions as an adaptor that links TLR-MyD88 signaling to B cell activation. Nat. Immunol. 13, 612-620 (2012).

23. Papatriantafyllou, M. et al. Dickkopf-3, an immune modulator in peripheral CD8 T-cell tolerance. Proc. Natl. Acad. Sci. USA 109, 1631-1636 (2012).

24. Griewank, K. et al. Homotypic interactions mediated by Slamf1 and Slamf6 receptors control NKT cell lineage development. Immunity 27, 751-762 (2007).
25. van Driel, B. et al. Signaling lymphocyte activation molecule regulates development of colitis in mice. Gastroenterology 143, 1544-1554 (2012).

26. Means, T.K. et al. Evolutionarily conserved recognition and innate immunity to fungal pathogens by the scavenger receptors SCARF1 and CD36. J. Exp. Med. 206, 637-653 (2009)

27. Alfaro, D. et al. EphrinB1-EphB signaling regulates thymocyte-epithelium interactions involved in functional T cell development. Eur. J. Immunol. 37 2596-2605 (2007)

28. Basu, A. et al. Cutting edge: Vascular endothelial growth factor-mediated signaling in human $\mathrm{CD} 45 \mathrm{RO}{ }^{+} \mathrm{CD} 4{ }^{+} \mathrm{T}$ cells promotes Akt and ERK activation and costimulates IFN- $\gamma$ production. J. Immunol. 184, 545-549 (2010).

29. Croft, M. Control of immunity by the TNFR-related molecule OX40 (CD134). Annu. Rev. Immunol. 28, 57-78 (2010).

30. Furuichi, K. et al. Chemokine receptor CCR1 regulates inflammatory cell infiltration after renal ischemia-reperfusion injury. J. Immunol. 181, 8670-8676 (2008)

31. Akimzhanov, A.M., Yang, X.O. \& Dong, C. Chromatin remodeling of interleukin-17 (IL-17)-IL-17F cytokine gene locus during inflammatory helper T cell differentiation. J. Biol. Chem. 282, 5969-5972 (2007).

32. Mukasa, R. et al. Epigenetic instability of cytokine and transcription factor gene loci underlies plasticity of the $T$ helper 17 cell lineage. Immunity 32, 616-627 (2010).

33. Schoenborn, J.R. et al. Comprehensive epigenetic profiling identifies multiple distal regulatory elements directing transcription of the gene encoding interferon- $\gamma$. Nat. Immunol. 8, 732-742 (2007).

34. Wang, X. et al. Transcription of il 17 and il $17 f$ is controlled by conserved noncoding sequence 2. Immunity 36, 23-31 (2012).

35. Turchinovich, G. \& Hayday, A.C. Skint-1 identifies a common molecular mechanism for the development of interferon- $\gamma$-secreting versus interleukin-17-secreting $\gamma \delta$ T cells. Immunity 35, 59-68 (2011).

36. Laird, R.M., Laky, K. \& Hayes, S.M. Unexpected role for the B cell-specific Src family kinase $B$ lymphoid kinase in the development of IL-17-producing $\gamma \delta$ T cells. J. Immunol. 185, 6518-6527 (2010)

37. de Almeida, S.F. et al. Splicing enhances recruitment of methyltransferase HYPB/ Setd2 and methylation of histone H3 Lys36. Nat. Struct. Mol. Biol. 18, 977-983 (2011).

38. Charles, K.A et al. The tumor-promoting actions of TNF- $\alpha$ involve TNFR1 and IL17 in ovarian cancer in mice and humans. J. Clin. Invest. 119, 3011-3023 (2009).

39. Lee, Y.K. et al. Late developmental plasticity in the T helper 17 lineage. Immunity 30, 92-107 (2009).

40. Veeck, J. \& Dahl, E. Targeting the Wnt pathway in cancer: the emerging role of Dickkopf-3. Biochim. Biophys. Acta 1825, 18-28 (2012)

41. Kaech, S.M., Hemby, S., Kersh, E. \& Ahmed, R. Molecular and functional profiling of memory CD8 T cell differentiation. Cell 111, 837-851 (2002).

42. Malhotra, N. et al. A network of high-mobility group box transcription factors programs innate interleukin-17 production. Immunity 38, 681-693 (2013).

43. Vahedi, G. et al. STATs shape the active enhancer landscape of T cell populations Cell 151, 981-993 (2012).

44. Durant, L. et al. Diverse targets of the transcription factor STAT3 contribute to T cell pathogenicity and homeostasis. Immunity 32, 605-615 (2010).

45. Shibata, K. et al. Notch-Hes1 pathway is required for the development of IL-17 producing $\gamma \delta$ T cells. Blood 118, 586-593 (2011).

46. Lochner, $\mathrm{M}$. et al. In vivo equilibrium of proinflammatory $\mathrm{IL}-17^{+}$and regulatory IL-10+Foxp3 ${ }^{+}$ROR t $^{+}$T cells. J. Exp. Med. 205, 1381-1393 (2008)

47. Carmi, Y. et al. Microenvironment-derived IL-1 and IL-17 interact in the control of lung metastasis. J. Immunol. 186, 3462-3471 (2011).

48. Hirota, K. et al. Fate mapping of IL-17-producing T cells in inflammatory responses. Nat. Immunol. 12, 255-263 (2011).

49. Sheridan, B.S. et al. $\gamma \delta \mathrm{T}$ cells exhibit multifunctional and protective memory in intestinal tissues. Immunity 39, 184-195 (2013).

50. Reynolds, J.M., Martinez, G.J., Chung, Y. \& Dong, C. Toll-like receptor 4 signaling in T cells promotes autoimmune inflammation. Proc. Natl. Acad. Sci. USA 109 , 13064-13069 (2012). 


\section{ONLINE METHODS}

Mice. All mice used were adults 6-12 weeks of age. C57BL/6, $\mathrm{Trra}^{-/-}$, $\mathrm{Rorc}^{-/-}$ and $T b \times 21^{-1-}$ mice were from Jackson Laboratories. Slamf1 $1^{-1-}$ and $D k k 3^{-1-}$ mice were provided by C. Terhorst and B. Arnold, respectively. Mice were bred and maintained in the specific pathogen-free animal facilities of Instituto de Medicina Molecular (Lisbon, Portugal) or Queen Mary London University (London, UK). All experiments involving animals were done in compliance with the relevant laws and institutional guidelines and were approved by the ethics committees of Instituto de Medicina Molecular and Blizard Institute.

Cell sorting or analysis by flow cytometry. For cell surface staining, singlecell suspensions were incubated for $15 \mathrm{~min}$ on ice with anti-Fc $\gamma \mathrm{R}(2.4 \mathrm{G} 2$; BD Pharmingen), and then for $30 \mathrm{~min}$ with saturating concentrations of the appropriate monoclonal antibody. The following monoclonal antibodies were used: eFluor 450-anti-CD4 (RM4-5), fluorescein isothiocyanate- or phycoerythrin-anti-TCR $\gamma \delta$ (GL3), peridinin chlorophyll protein-cyanine 5.5-anti-CD3ع (145.2C11), phycoerythrin-indotricarbocyanine-anti-CD27 (LG.7F9), allophycocyanin-anti-CD25 (PC61 5.3), allophycocyanin-eFluor 780-anti-CD8 (53-6.7; all from eBiosciences); and Alexa Fluor 647-anti-CCR6 (29-2L17; BD Pharmingen). For sorting of T cell subsets, lymphoid organs were pooled from four mice (quantitative RT-PCR) or eight mice (ChIP-qPCR or ChIPseq). Cells were sorted on FACSAria III (BD Biosciences) or were analyzed on a FACSFortessa or FACSCalibur (BD Biosciences) and data were analyzed with FlowJo software (Tree Star).

For intracellular cytokine staining, cells sorted by flow cytometry were stimulated for $4 \mathrm{~h}$ at $37^{\circ} \mathrm{C}$ with PMA (phorbol 12-myristate 13 -acetate; $50 \mathrm{ng} / \mathrm{mL}$ ) and ionomycin $(1 \mu \mathrm{g} / \mathrm{mL}$ ) (Sigma) with $10 \mu \mathrm{g} / \mathrm{mL}$ brefeldin A (Sigma) added during the final $2 \mathrm{~h}$. Cells were stained (with antibodies identified above), fixed for $15 \mathrm{~min}$ at $4{ }^{\circ} \mathrm{C}$ with $2 \%$ paraformaldehyde, permeabilized for $30 \mathrm{~min}$ at room temperature with $0.5 \%$ saponin and $0.1 \%$ FCS in 2 mM EDTA-PBS in the presence of anti-Fc $\gamma \mathrm{R}$ (2.4G2; BD Pharmingen) and finally incubated for $1 \mathrm{~h}$ at room temperature with fluorescein isothiocyanate-anti-IL-17 (17B7; eBiosciences) and allophycocyanin-anti-IFN- $\gamma$ (XMG1.2; eBiosciences).

In vitro cell stimulation and polarization. $\mathrm{CD} 27^{+}$and $\mathrm{CD} 27-\gamma \delta \mathrm{T}$ cells were sorted by flow cytometry and subjected to various stimulation conditions for $48 \mathrm{~h}$; $\mathrm{CD}^{+} \mathrm{T}$ cell-polarization cultures were maintained for $6 \mathrm{~d}$. For $\mathrm{T}_{\mathrm{H}} 1$ culture conditions, cells were activated with plate-bound monoclonal antibody (mAb) to CD3e ( $5 \mu \mathrm{g} / \mathrm{ml} ; 145.2 \mathrm{C} 11$; eBiosciences) and soluble $\mathrm{mAb}$ to $\mathrm{CD} 28(1 \mu \mathrm{g} / \mathrm{ml} ; 37.51$; eBiosciences), in the presence of IL-12 (5 ng/ml) and neutralizing mAb to IL-4 (10 $\mu \mathrm{g} / \mathrm{ml} ; 11 \mathrm{~B} 11$; eBiosciences $)$. For $\mathrm{T}_{\mathrm{H}} 17 \mathrm{cul}$ ture conditions, cells were activated with plate-bound anti-CD3e, and soluble anti-CD2 8 and TGF- $\beta$ ( $2 \mathrm{ng} / \mathrm{ml})$, IL- $1 \beta$ (10 ng/ml), IL-6 $(20 \mathrm{ng} / \mathrm{ml})$, IL-21 $(100 \mathrm{ng} / \mathrm{ml}), \mathrm{IL}-23(10 \mathrm{ng} / \mathrm{ml})$ and neutralizing anti-IFN- $\gamma(10 \mu \mathrm{g} / \mathrm{ml})$ were added to the medium. Alternatively, cells were incubated on plate-bound $\mathrm{mAb}$ to CD3E $(5 \mu \mathrm{g} / \mathrm{ml})$, in the presence or absence of mouse IL-7 $(10 \mathrm{ng} / \mathrm{ml})$ or IL-1 $\beta$ plus IL-23 (both at $10 \mathrm{ng} / \mathrm{ml}$ ).

ChIP-seq and ChIP-qPCR. Cells were sorted by flow cytometry from the thymus or pooled spleen and lymph nodes for ChIP. The following antibodies were used: antibody to histone $\mathrm{H} 3$ (ab1791; Abcam), antibody to H3K36me3 (ab9050; Abcam), antibody to acetylated histone H3 (06-599; Millipore), antibody to H3K4me2 (07-030; Millipore) and antibody to H3K27me3 (07-449; Millipore).

Cells $\left(1 \times 10^{5}\right.$ to $\left.1 \times 10^{6}\right)$ were crosslinked with formaldehyde and nuclei were isolated and sonicated with a Sanyo Soniprep 150 at an amplitude of $10 \mathrm{~mm}$ with 17 bursts of $10 \mathrm{~s}$, which resulted in chromatin fragments 200-400 bp in length. Chromatin was immunoprecipitated as described ${ }^{51}$. The immunoprecipitated DNA released from crosslinked proteins was extracted with a QiaQuick kit in accordance with the manufacturer's instructions (Qiagen).

Deep sequencing was done at the GeneCore facility of the European Molecular Biology Laboratory. At least $1 \mathrm{ng}$ of immunoprecipitated DNA was used for library preparation according to the Illumina protocol.

Alternatively, candidate genes were analyzed by ChIP-qPCR (primers, Supplementary Table 3 ).

The occupancy of the immunoprecipitated protein at each DNA site was estimated as follows: $2^{(\text {Cspecific }-C \text { totalH3) }}$ where, $C_{\text {specific }}$ and $\mathrm{C}_{\text {totalH3 }}$ are threshold cycles of PCR of DNA from specific immunoprecipitation or total H3 immunoprecipitation, respectively.

ChIP-seq data analysis. High-throughput sequencing 'reads' were aligned to the reference mouse genome (the $\mathrm{mm} 9$ assembly of the National Center for Biotechnology Information) with Bowtie software for the alignment of short DNA sequences ${ }^{52}$. 'Read' quality was assessed with the FastQC quality-control tool for high throughput sequence data (Babraham Bioinformatics). 'Reads' with bad-quality scores, 'reads' not uniquely mapped and PCR duplicates (identical coordinates) were filtered out. The SAMtools utility for storing large nucleotide sequence alignments and manipulating alignments ${ }^{53}$ and BEDtools software for the comparison of genomic features ${ }^{54}$ were used for filtering steps and file format conversion. Three different peak-calling tools (MACS ${ }^{55,56}$, SICER $^{57}$ and $\mathrm{RSEG}^{58}$ ) were used for the detection of enrichment of histone modifications density. The recommended settings for histone modifications were used for these analyses, and only peaks that were consistently detected by the three methods were considered. Regions with different histone-modification densities in two samples were identified with the submodule of SICER ${ }^{57}$, with a false-discovery rate of 0.05 and absolute change in density $>1.5$-fold.

Regions with enrichment were then assigned to known genes of the UCSC Genome Browser, including a 1-kilobase region upstream of transcription start site (the mm9 assembly of the mouse genome of the National Center for Biotechnology Information) ${ }^{59}$.

For quantitative calculation and profiles of histone modifications for all genes, uniquely mapped 'reads' were extended in the 3 ' direction to reach 150 nt with the Pyicos deep-sequencing analysis tool ${ }^{60}$. Only 'read' counts that overlapped histone-enriched regions identified above were considered. The quantitative results per gene were $\log _{10}$-transformed. For genes without enriched regions, the amount was defined as 0 .

For average profiles across genes with differences in histone densities, a 'metagene' profile was plotted for each gene group. Genes were aligned at the first and last nucleotides of the annotated transcripts and sequencing tags were scaled as follows: the $5^{\prime}$ end ( $2 \mathrm{~kb}$ upstream of the transcription start site to $1 \mathrm{~kb}$ downstream) and the $3^{\prime}$ end (500 bp upstream of the poly(A) site to $1 \mathrm{~kb}$ downstream) were unscaled and averaged in a 10-bp window, and the remainder of the gene was scaled to 200 bins of equal size so that all genes seem to have the same length $(2 \mathrm{~kb})$. Individual profiles were produced with a window of $5 \mathrm{bp}$. All profiles were plotted on a normalized reads-per-million basis. The processed data were plotted and visualized using software of the R project for statistical computing ${ }^{61}$.

Real-time PCR. Cell populations were sorted by flow cytometry and mRNA was prepared from those with a High Pure RNA Isolation kit (Roche). Random oligonucleotides (Invitrogen) and MMLV reverse transcriptase (Promega) were used for reverse transcription for $1 \mathrm{~h}$ at $42{ }^{\circ} \mathrm{C}$. SYBR or TaqMan probe chemistry on an ABI ViiA7 cycler (Applied Biosystems) was used for quantification of specific cDNA species relative to that of $A c t b$. The cycling threshold $\left(C_{t}\right)$ for the target gene was subtracted from that of $A c t b$ and the relative amount was calculated as $2^{-\Delta \mathrm{Ct}}$. Primers were designed with Primer Express software (Applied Biosystems) and their sequences were as follows: Actb forward, CGTGAAAAGATGACCCAGATCA, and reverse, TGGTACGACCAGAGGCATACAG; $B l k$ forward, TTATGTGC CCAGCAACTTTGTG, and reverse, AAGGCACCTTTATTGCTCTCA CTCT; Eomes forward, CGTTCACCCAGAATCTCCTAACA, and reverse, TGCAGCCTCGGTTGGTATTT; Hlx forward, AGCTCCAACCCAAGA AATTCTGT, and reverse, GCTTGTATGTCTGTGGCATGGT; probe, ACA CATTTCCAGGTCCCTATGCTGTGCTC; Ifng forward, TCTTCTTGG ATATCTGGAGGAACTG, and reverse, GAGATAATCTGGCTCTGCAG GATT; $I l 17 a$ forward, CCAGAAGGCCCTCAGACTACCT, and reverse, TCCCTCCGCATTGACACA; Ill $f$ forward, CAACCAAAACCAGGGCATTT, and reverse, ACTGGGCCTCAGCGATCTCT; Il22 forward, GTGCCTTT CCTGACCAAACT, and reverse, CTGTCTCCTTCAGCCTTCTG; Il $23 r$ forward, TCAGTGCTACAATCTTCAGAGGACA, and reverse, GCCAA GAAGACCATTCCCGA; Maf forward, AGCAGGTAGACCACCTCAA GCA, and reverse, GAGTCCCTTGGGTACATGAAAAATT; Rora forward, TCCCCTACTGTTCCTTCACCAA, and reverse, GGAAGGTCTGCCACG TTATCTG; Rorc forward, GTCCAGACAGCCACTGCATTC, and reverse, 
TGCGCTGCCGTAGAAGGT; Runx3 forward, ACTGGCGCTGCAACAA GAC, and reverse, GGCCCACGAATCGAAGGT; and Tbx21 forward, CACACACGTCTTTACTTTCCAAGAGA, and reverse, CACTCGTATCAA CAGATGCGTACAT.

Tumor transplantation. ID8 ovarian cancer cells (provided by K. Roby) were injected intraperitoneally into C57BL/ 6 female mice $\left(5 \times 10^{6}\right.$ cells per mouse). Tumor growth was monitored as described ${ }^{38}$. Peritoneal exudate cells were collected 2-6 weeks after tumor transplantation, then were stimulated in vitro for $4 \mathrm{~h}$ with PMA and ionomycin and stained intracellularly for IL-17 and IFN- $\gamma$.

Infection. Mice were infected intraperitoneally with $1 \times 10^{6}$ red blood cells infected with Plasmodium berghei ANKA with transgenic expression of GFP (provided by A. Pamplona) and were monitored as previously described ${ }^{10}$. Cells from the spleen and lymph nodes were collected for analysis after $3 \mathrm{~d}$.

Mice were infected intraperitoneally with $1 \times 10^{6}$ plaque-forming units of murid herpes virus 4 (provided by P. Simas), and cells from the spleen and lymph nodes were collected after $14 \mathrm{~d}$.

Mice were infected intravenously with $1 \times 10^{6}$ colony-forming units of Mycobacterium avium strain 2447 (provided by M. Correia-Neves). Cells from the spleen and lymph nodes were collected $17 \mathrm{~d}$ after infection. Infection was confirmed by serial dilutions of homogenized spleen plated onto Middlebrook 7H10 agar.

Mice were infected intravenously with $1 \times 10^{5}$ live Candida albicans yeast strain WT-SC 3314 (provided by C. Reis e Sousa). Cells from the spleen and lymph nodes were collected $7 \mathrm{~d}$ after infection. Infection was confirmed by serial dilutions of homogenized kidney suspension plated onto yeast extract peptone dextrose agar medium.

Statistical analysis. A two-tailed non-parametric Mann-Whitney test was used for statistical analysis. $P$ values of $<0.05$ were considered significant.

51. Schnekenburger, M., Talaska, G. \& Puga, A. Chromium cross-links histone deacetylase 1-DNA methyltransferase 1 complexes to chromatin, inhibiting histoneremodeling marks critical for transcriptional activation. Mol. Cell. Biol. 27, 7089-7101 (2007).

52. Langmead, B., Trapnell, C., Pop, M. \& Salzberg, S.L. Ultrafast and memory-efficient alignment of short DNA sequences to the human genome. Genome Biol. 10, R25-R35 (2009).

53. Li, H. et al. The Sequence Alignment/Map format and SAMtools. Bioinformatics 25, 2078-2079 (2009)

54. Quinlan, A.R. \& Hall, I.M. BEDTools: a flexible suite of utilities for comparing genomic features. Bioinformatics 26, 841-842 (2010),

55. Zhang, Y. et al. Model-based analysis of ChIP-Seq (MACS). Genome Biol. 9 R137-R146 (2008)

56. Feng, J., Liu, T. \& Zhang, Y. Using MACS to identify peaks from ChIP-Seq data. Curr Protoc Bioinformatics 34, 2.14.1-2.14.14 (2011).

57. Zang, C. et al. A clustering approach for identification of enriched domains from histone modification ChIP-Seq data. Bioinformatics 25, 1952-1958 (2009).

58. Song, Q. \& Smith, A.D. Identifying dispersed epigenomic domains from ChIP-Seq data. Bioinformatics 27, 870-871 (2011).

59. Rhead, B. et al. The UCSC Genome Browser database: update 2010. Nucleic Acids Res. 38, D613-D619 (2010).

60. Althammer, S., Gonzalez-Vallinas, J., Ballare, C., Beato, M. \& Eyras, E. Pyicos: a versatile toolkit for the analysis of high-throughput sequencing data. Bioinformatics 27, 3333-3340 (2011)

61. R Core Team. R: A Language and Environment for Statistical Computing (R Foundation for Statistical Computing, Vienna, 2013). 